\title{
Waist hip ratio: an anatomical predictive marker of risk of PCOS
}

\author{
Sumitra Yadav*, Ritu Tarware
}

Department of Obstetrics and Gynecology, MGMMC, Indore, Madhya Pradesh, India

Received: 09 February 2019

Accepted: 14 March 2019

\section{*Correspondence: \\ Dr. Sumitra Yadav, \\ E-mail: drsumitrayadav@yahoo.co.in}

Copyright: () the author(s), publisher and licensee Medip Academy. This is an open-access article distributed under the terms of the Creative Commons Attribution Non-Commercial License, which permits unrestricted non-commercial use, distribution, and reproduction in any medium, provided the original work is properly cited.

\section{ABSTRACT}

Background: Polycystic ovarian syndrome (PCOS) is one of the most common endocrine disorders seen in infertility clinic of Gynae OPD. It is basically is disease of metabolic disorder and requires ultrasound and hormonal assay for its diagnosis.

Methods: The study was carried out in the GOPD of MGM medical College and M.Y. Hospital Indore (M.P.) India. It included 200 women in the age group 18-40 years diagnosed as PCOS and who were compared with 200 women of same age group without PCOS. The height, weight BMI and waist hip ratio were measured and analyzed statistically. Results: The present study shows that women with PCOS had higher incidence of acne hirsutism and irregular menses $(\mathrm{p}<0.0001)$, women with PCOS had higher mean ovarian volume measurement $(11 \pm 1.4 \mathrm{cc})$ compared to female controls who had lower volume of ovary with a range of $(7.94 \pm 2.34 \mathrm{cc}$. $(\mathrm{p}<0.0001)$ as calculated by USG by sonologist.

Conclusions: The presence of central obesity, (waist hip ratio >0.87) is an indication for presence of PCOS. Thus, these patients may undergo further hormone evaluation and this simple measurement can help to screen out PCOS from general population. This prevents financial burden on low resource settings.

Keywords: BMI, Metabolic disorder, PCOS

\section{INTRODUCTION}

Polycystic ovarian syndrome (PCOS) is one of the most common endocrine disorder affecting approximately $5 \%$ $8 \%$ of premenopausal women. ${ }^{1}$ PCOS also called Hyperandrogenic Anovulation or Stein Leventhal syndrome has diverse range of causes and it peruse etiology is unknown but there is a strong evidence that it is a genetic disease..$^{2,3}$

It produces symptoms in approximately $5-10 \%$ of women of reproductive age. and is thought to be the leading cause of female sub fertility. ${ }^{4}$ Excess androgen is attributed to be one of the causes. There are varied data of prevalence of PCOS, in different population. The tests to detect PCOS are generally quite expensive such as hormone assays and ultrasonography. Since PCOS is related to obesity, women with PCOS particularly those with central obesity are at higher risk of development of metabolic syndrome and insulin resistance worsens insulin related metabolic and reproductive features of PCOS including dyslipidemia, anovulation, hyperandrogenemia.

Authors decided to conduct a study to determine if PCOS could he predicted by waist hip ratio $(\mathrm{W}: \mathrm{H})$.

\section{METHODS}

The present prospective study was conducted in Gynaecological OPD of MY hospital and M.G.M. Medical College Indore (M.P.) India. 


\section{Inclusion criteria}

- It included 200 women in each group (case and control) of age group 18-40 years which were diagnosed cases of PCOS either by a reproductive endocrinologist or gynecologist on the basis of clinical history to determine menstrual irregularities or duration of infertility.

- Ultrasonography to detect the presence or absence of Polycystic ovaries.

- $\quad$ These cases were compared with 200 regular cycling women of the same age group without PCOS

\section{Exclusion criteria}

- Subject below 18 years and above 40 years.

- Subjects with other aetiologies of androgen excess and anovulatory infertility such as hyperprolactinemia thyroid dysfunction and congenital adrenal hyperplasia.

- Subject with pathological causes of oedema, hypertension and patients on drugs like diuretics, steroids which can affect vascular and extra vascular volume were also excluded.

\section{RESULTS}

Anthropometic measurements included a waist circumference in centimeters measured at the narrowed circumference midway between the upper border of iliac crest and the lower rib margin where the hip circumference was taken as the widest measurement at the level of the greater trochanters.

Table 1: Distribution of acne hirsutism and irregular menses in case and controls.

\begin{tabular}{|l|l|l|l|l|}
\hline Group & Cases & \multicolumn{3}{c|}{ Controls } \\
\hline & $\mathbf{N = 2 0 0}$ & $\mathbf{\%}$ & $\mathbf{N = 2 0 0}$ & $\mathbf{\%}$ \\
\hline Acne (A) & 64 & 64 & 22 & 22 \\
\hline Hirsutism (H) & 62 & 62 & 08 & 08 \\
\hline Irregular Menses (I) & 84 & 84 & 03 & 03 \\
\hline & 200 & & 200 & \\
\hline
\end{tabular}

Height was recorded in $\mathrm{cms}$ and weight in kilogram. Body mass index BMI was calculated as weight in kilogram divided by square of height in meters $\left(\mathrm{Kg} / \mathrm{m}^{2}\right)$. Table 1 highlights that majority of the cases $(84 \%)$ presented with irregular menses followed by hirsutism in $62 \%$ and acne in $64 \%$ of the cases as the chief complaint.

Table 2: Distribution according to anthropometric parameters.

\begin{tabular}{|c|c|c|c|c|c|c|}
\hline $\begin{array}{l}\text { T Test } \\
\text { cases/controls }\end{array}$ & $\begin{array}{l}\text { Weight }(\mathbf{k g}) \\
\text { cases }\end{array}$ & $\begin{array}{l}\text { Weight (kg) } \\
\text { control }\end{array}$ & $\begin{array}{l}\text { Height (m) } \\
\text { cases }\end{array}$ & $\begin{array}{l}\text { Height (m) } \\
\text { control }\end{array}$ & $\begin{array}{l}\text { BMI } \\
\text { cases }\end{array}$ & $\begin{array}{l}\text { BMI } \\
\text { controls }\end{array}$ \\
\hline Minimum & 45 & 43 & 1.50 & 1.52 & 17.15 & 17.24 \\
\hline Maximum & 82 & 76 & 1.72 & 1.72 & 32.05 & 30.44 \\
\hline Mean & 65.54 & 60.31 & 1.59 & 1.59 & 25.79 & 23.86 \\
\hline SD & 8.32 & 6.65 & 0.038 & 0.030 & 3.09 & 2.53 \\
\hline SE & 0.832 & 0.665 & 0.003 & 0.003 & 0.309 & 0.253 \\
\hline t Value & \multicolumn{2}{|l|}{4.90} & \multicolumn{2}{|l|}{0.90} & \multicolumn{2}{|l|}{4.82} \\
\hline P Value & \multicolumn{2}{|c|}{$\mathrm{p}<0.0001$} & \multicolumn{2}{|l|}{$\mathrm{p}<0.367$} & \multicolumn{2}{|c|}{$\mathrm{p}<0.0001$} \\
\hline Significance & \multicolumn{2}{|c|}{$* * *$ Highly Significant } & \multicolumn{2}{|c|}{ Not Significant } & \multicolumn{2}{|c|}{ ***Highly Significant } \\
\hline
\end{tabular}

Table 3: Distribution according to age.

\begin{tabular}{|l|l|l|}
\hline t Test cases/controls age & Age cases & Age control \\
\hline Minimum & 19 & 19 \\
\hline Maximum & 35 & 36 \\
\hline Mean & 23.26 & 24.35 \\
\hline SD & 3.56 & 3.69 \\
\hline SE & 0.356 & 0.369 \\
\hline t Value & 2.13 & \\
\hline P Value & p $<0.0347$ \\
\hline Significance & *Significant \\
\hline
\end{tabular}

Table 2 shows that PCOS is significantly associated with weight and BMI in comparison to height which was found to be non-significant. Table 3 shows that PCOS is significantly associated with age. As p-value is $<0.0347$ so this is found to be a significant association. Table 4 shows the mean age of $23.26 \pm 3.56$ years and $24.35 \pm 3.69$ years respectively in the group of cases and controls.

Table 4: Observation and results distribution according to age.

\begin{tabular}{|l|l|l|l|}
\hline & Cases & Controls & p Value \\
\hline Age and years & $23.26 \pm 3.56$ & $24.35 \pm 3.69$ & $<0.0347$ \\
\hline
\end{tabular}

Table 5: Waist hip ratio.

\begin{tabular}{|l|l|l|l|}
\hline $\begin{array}{l}\text { Waist hip ratio } \\
\text { (WHR) }\end{array}$ & $0.87 \pm 0.05$ & $0.82 \pm 0.05$ & $<0.0001$ \\
\hline
\end{tabular}


Table 5 shows WHR $>0.8$ is significantly associated with the PCOS and thereby reflecting its effect on the patient's clinical features, metabolic disturbances and endocrine profile.

\section{DISCUSSION}

Androgen excess in utero may support the presence of unfavorable metabolic state leading to dyslipidemia and contract distribution of fat (android patters) which in turn leads to PCOS. ${ }^{6}$ The present study shows that women with PCOS had higher incidence of acne, hirsutism and irregular menses with p-value $<0.0001$. Women with PCOS had higher mean ovarian volume measurement $(11 \pm 1.4 \mathrm{cc})$ compared to female controls who had literally equal volume of ovary with a range of $(7.94 \pm 2.34 \mathrm{cc})$ with p-value $<0.0001$ as calculated by USG by sonologist. ${ }^{7}$

In a study on Brazilian women with PCOS the prevalence of metabolic syndrome was found to increase with BMI : $3.2 \%, 19.2 \%$, and $52.3 \%$ for normal over weight and Obese women respectively. ${ }^{8}$ In present study we find that height of the women does not correlate well with the prediction of PCOS with $\mathrm{p}$-value $<0.367$ which was not significant while if you take only weight, it is predictive of PCOS with p-value $<0.0001$ which was found to be highly significant. Thereby proving that obesity has a correlation with PCOS. When you compare BMI for these women again in the case studies comparing it with controls, BMI prediction was highly significant for PCOS ( $\mathrm{p}$ value $<0.0001$ )

A Dutch study reported that a waist circumference $>83.5$ $\mathrm{cm}$ along with biochemical evidence of hyperandrogenism was a powerful prediction of the presence of metabolic syndrome and insulin résistance. ${ }^{9}$ Waist Hip ratio was a better predictor of metabolic syndrome in women with PCOS compared to other predictors including BMI. In present study, parameter of obesity, being a good predictor of PCOS, in the control group is in agreement with Janssen et al.

Janssen et al concluded that waist circumference is closely related to obesity related risk factor as compared with BMI. ${ }^{10}$ This is also in agreement with all WHR $>0.8$ are correlated significantly with the PCOS and reflecting its effect on the patients clinical features, metabolic disturbances and endocrine profile. ${ }^{11}$

Screening for all infertility women with PCOS would be ideal, but in our country with low resources, it seems farfetched so if authors can identify women and then screen them it would be saving lot of resources. Present study has some limitations as authors could not co-related present findings with hormone assays as they were not available in present settings.

\section{ACKNOWLEDGMENTS}

Authors would like to thank Dr. V. K. Pandit, Department of Anatomy for the support during study.

Funding: No funding sources

Conflict of interest: None declared

Ethical approval: The study was approved by the Institutional Ethics Committee

\section{REFERENCES}

1. Frank S. Polysystic ovary syndrome. N Engl J Med. 1995;333(13):853-61.

2. Kellmann M, Martins, WP, Raine Fenning N, Terms and thresholds for the ultrasound evaluation of the ovaries in women with hyperandrogenic anovulation. Hum Reprod. 2014;20(3):463-64

3. Diamanti - Kandaraskin E, KAndaraskin H, Hegeo RS : The role of genes and environment in the etiology of PCOS. Endo 2006;30(1):19-26

4. Dumesic DA, Abbott DH, Eisner JR, Goy RW. Prenatal exposure of female rhesus monkeys to testosterone propionate increases serum luteinizing hormone levels in adulthood. Fertil Steril. 1997 ;67(1):155-63.

5. Abbott DH, Dumesic DA, Franks, Developments origin of polycystic ovary syndrome- a hypothesis. J Endocrinol. 2002;174(1):1-5

6. Eckel RH, Grundy SM, Zimmet PZ. The metabolic syndrome, Lancet. 2005; 365(9468):1415-28.

7. Kennedy A. Polycystic ovarian syndrome. In Ahuja AT (ed) Diagnostic imaging Ultra Sound. 1st ed. Canada , Amirsy / Elsevir, 2007 p. 94-95

8. Soares EM, Azevedo GD, Gadelha RG, Lemos TM, Maranhão TM. Prevalence of the metabolic syndrome and its components in Brazilian women with polycystic ovary syndrome. Fertil Steril. 2008;89(3):649-55.

9. Goverde AJ, Van Koert AJ, Eijkemans MJ, Knauff EA, Westerveld HE, Fauser BC, Broekmans FJ. Indicators for metabolic disturbances in anovulatory women with polycystic ovary syndrome diagnosed according to the Rotterdam consensus criteria. Hum Reproduct. 2008;24(3):710-7.

10. Janssen I, Katzmarzyk PT, Ross R. Waist circumference and not body mass index explains obesity-related health risk. Am J Clinic Nutri. 2004;79(3):379-84

11. Mandrelle K, Kamath MS, Bondu DJ, Chandy A, Aleyamma TK, George K. Prevalance of metabolic syndrome in women with polycystic ovary syndromeattending an infertility clinic in atertiary care hospital in South India. J Hum Reprod Sci. 2012;5(1):26-31.

Cite this article as: Yadav S, Tarware R. Waist hip ratio: an anatomical predictive marker of risk of PCOS. Int J Reprod Contracept Obstet Gynecol 2019;8:1630-2. 